\title{
Substrate-borne vibrations used during acoustic communication and the existence of courtship songs in some species of the genus Anaxipha (Saussure) (Orthoptera: Trigonidiidae: Trigonidiinae)
}

\author{
WILBUR L. HERSHBERGER'
}

1 Hedgesville, West Virginia 25427, USA.

Corresponding author: Wilbur L. Hershberger (Wilhershberger@mac.com)

Academic editor: Klaus-Gerhard Heller | Received 2 July 2021 | Accepted 17 September 2021 | Published 14 December 2021

http://zoobank.org/49303DCD-3FE3-42E2-A436-9403D3663640

Citation: Hershberger WL (2021) Substrate-borne vibrations used during acoustic communication and the existence of courtship songs in some species of the genus Anaxipha (Saussure) (Orthoptera: Trigonidiidae: Trigonidiinae). Journal of Orthoptera Research 30(2): 185-191. https://doi.org/10.3897/ jor.30.70990

\begin{abstract}
Anaxipha (Saussure, 1874) are small, swordtail crickets found in much of eastern North America. Many species within the genus Anaxipha were only recently described and their calling songs characterized. However, little is known about their courtship songs or use of substrate-borne communication (drumming). This study is the first documentation of the existence of courtship songs and substrate-borne vibrational communication in the genus. Courtship songs and substrate-borne vibrational communication were first detected in the following species: Anaxipha exigua (Say, 1825), A. tinnulacita Walker \& Funk, 2014, A. tinnulenta Walker \& Funk, 2014, and A. thomasi Walker \& Funk, 2014. When in the presence of a conspecific female, males of all four species perform courtship songs that are distinctly different in pattern of echeme delivery and syllable details compared to their respective calling songs. Additionally, males of all four species exhibited drumming behavior during courtship singing and variably during calling songs. Examination of video recordings of males drumming during courtship singing showed that they are apparently using the sclerotized portion of their mandibles to impact the substrate on which they are perched to create vibrations. Courtship song and drumming bout characteristics were statistically different among the four species studied here, although A. tinnulacita and A. tinnulenta were similar in some measurements. Drumming during calling songs was common only in A. tinnulacita, where drumming occurs predominately during the first forty percent and last twenty percent of the long echemes of calling songs. Additional study is needed to further explore the use of substrate-borne vibrational communication in this genus.
\end{abstract}

\section{Keywords}

communication, courtship, courtship song, drumming, echeme, substrateborne vibrations, vibration

\section{Introduction}

Large numbers of species of small insects use substrate-borne vibrations for near-field communication with conspecifics (Caldwell 2014, Yack 2016). Many of these species inhabit herbaceous and woody plants and use the plant's stems and leaves to transmit these vibrational signals (Michelsen et al. 1982, Eriksson et al. 2011). Small, plant-inhabiting insects that produce acoustic signals to attract mates most likely face challenges when trying to locate a singing male once the female is within a meter or so of the singer (Cocroft et al. 2000, Cokl and Virant-Doberlet 2003). Within the tangles of vegetation that these insects inhabit, the use of substrate-borne vibrations, in addition to acoustic signals, would be beneficial. This would allow for orientation toward and then finding of potential mates once the searcher is on, or close to, the stem or leaf from which the male is communicating (Hill 2001).

All the species of Anaxipha (Saussure, 1874) in this study are tiny insects, less than $8 \mathrm{~mm}$ in length, and occur on a wide variety of plants and plant structures in North America (Walker and Funk 2014). Males often sing from concealed perches, typically on the underside of leaves or stems, and are difficult to locate visually. Males sing calling songs, both day and night, which are loud and easily heard at distances of several meters (Walker and Funk 2014). Only at night can males and females be found foraging on the top side of vegetation or wandering along stems. In this study, the existence of courtship songs and drumming in the four Anaxipha species found in West Virginia are documented.

\section{Materials and methods}

Males and females of A. exigua (Say, 1825), A. tinnulacita Walker \& Funk, 2014, A. tinnulenta Walker \& Funk, 2014, and A. thomasi Walker \& Funk, 2014 were collected in August and September during the years of 2019 and 2020 from appropriate habitats (shrubs, coarse weeds, and grasses at the edges or the understory of deciduous woods) in Berkeley and Jefferson Counties in West Virginia, USA. As in Hershberger (2021), all specimens were maintained in plastic containers that were modified by removing most of the plastic from the sides and lid. The open areas were then covered with no-see-um netting held in place with high-temperature hot glue. These singing cages are practically transparent to sound. The crickets were fed iceberg lettuce, Fluker's High-calcium Cricket Diet (Port Allen, LA), and water ad libitum. Audio recordings of calling songs were made with caged, individual males placed in an anechoic room, with dim or no light. Temperatures were taken 


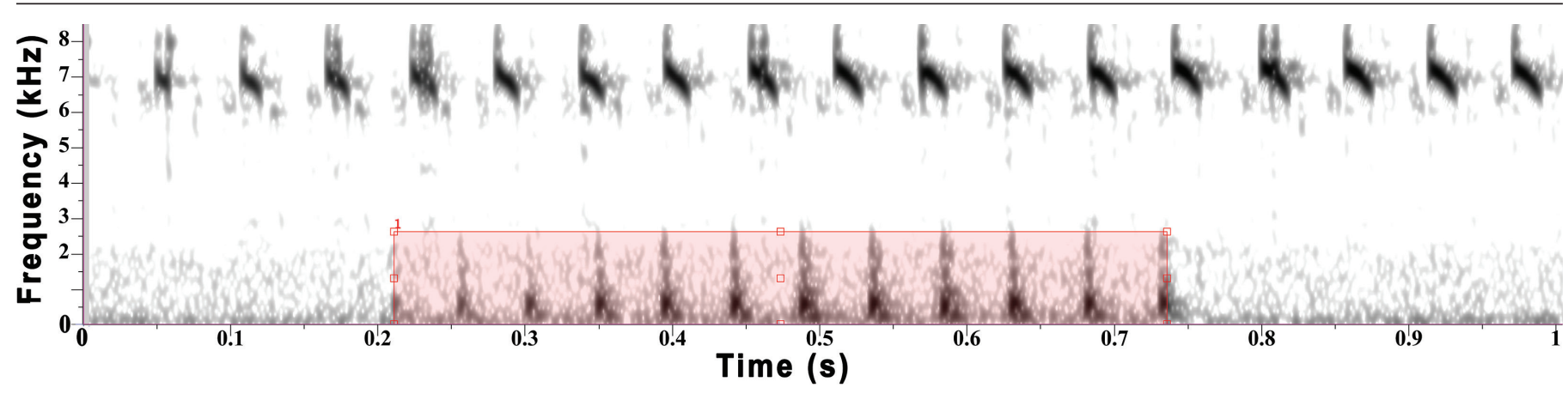

Fig. 1. A typical drumming bout showing the low-frequency and brief nature of these sounds. The figure is the selection of a drumming bout from a courtship song of $A$. thomasi showing the selection window spanning from the middle of the first tap to the middle of the last tap. This tapping bout consists of 12 taps.

with either a Cooper Atkins DFP450W digital pocket thermometer (Middlefield, CT, USA) or a Digi-Sense ZM-94460-78 receiver and ZM-90205-10 transmitter (Vernon Hills, IL, USA). Recordings were made with a Sound Devices 702, Sound Devices MixPre-6 (Reedsburg, WI, USA), or a Zoom F8n digital recorder (Hauppauge, NY, USA) at a sampling rate of $96 \mathrm{kHz}$ at 24-bit depth. The microphone, a Sennheiser MKH 8020 RF condenser (Solrød Stand, Denmark), was placed within $8 \mathrm{~cm}$ of the singing males. Audio recordings were processed using Adobe Audition CC 2020 (San Jose, CA, USA) and examined using Raven Pro v 1.6.1 (Cornell Lab of Ornithology). Data analysis was performed using Microsoft Excel (Redmond, WA, USA) and DataGraph software (Chapel Hill, NC, USA).

Acoustic terminology follows Baker and Chesmore (2020): a unit of sound produced by one closing stroke of the cricket tegmina is called a syllable; syllables are grouped into short echemes that are organized into calling songs or courtship songs.

Courtship songs were recorded by placing a female into the cage with the male, placing the cage in a dimly lit anechoic room, and allowing the insects to interact. A minimum of three different males were used for capturing courtship songs for each species. Three to four females were used for different courtship sessions. The recordings were made using the same equipment and techniques described for recording calling songs.

Videos of courtship behavior were made by placing a male and female of the same species into a clear, plastic container with a removable lid. A hole was cut into the lid and covered with no-seeum netting. Video was captured through the side of the clear enclosure using a Canon 5DSR digital camera with a Canon $180 \mathrm{~mm}$ macro lens with or without a $22 \mathrm{~mm}$ extension tube (Huntington, NY, USA). Lighting was provided by a table lamp with a 40 -wattequivalent LED bulb (to reduce heat). Audio was simultaneously recorded using the Sound Devices 702 digital audio recorder and a Sennheiser ME62 electret-condenser microphone (Solrød Stand, Denmark) placed within a few millimeters of the netting-covered hole of the enclosure. Video was edited in Final Cut Pro X (Apple Corp., Cupertino, CA, USA). All audio and video files are archived at the Macaulay Library, Cornell Laboratory of Ornithology (audio files are ML numbers 305982-306011. Video files are ML number 488780-488784).

Calling songs and courtship songs were processed in Adobe Audition to amplify the frequency band from $0-2 \mathrm{kHz}$ by $10-$ $30 \mathrm{~dB}$ to make it easier to detect the drumming bouts in Raven Pro 1.6.1. Drumming bouts were selected by hand from the middle of the first tap's signature through the middle of the last tap's signature in each tapping bout (Fig. 1). The tapping rate (taps/sec) was determined by dividing the number of taps in the bout, minus one, by the duration of the tapping bout in seconds. The syllable rate for the calling and courtship songs was determined at several haphazardly chosen times during the song. Syllables were selected from the beginning of one syllable through to the beginning of the eleventh syllable and dividing ten by the measured time (in seconds). Several measurements were averaged, and standard deviations were calculated for each recording. To show that taps within an individual drumming bout increase in amplitude, I selected the first two taps and the last two taps from each drumming bout in several courtship songs for each species. This created an average power (dBFS) for each selection. The means for the first two and the last two taps were compared using a $t$-test of the means. To determine the peak carrier frequency of the tapping bouts, I selected all drumming bouts from several courtship songs for each species, allowing Raven Pro v 1.6.1 to determine the peak frequency of the sounds within the selections. These were averaged and standard deviations calculated in DataGraph. The data were not heavily skewed, so means were compared using $t$-tests to calculate $p$-values using SciStat.com comparison of means calculator (https://www. scistat.com/statisticaltests/comparison_of_means.php).

\section{Results}

All four species produced calling songs consistent with the descriptions in Walker and Funk (2014). Analysis of audio recordings of calling songs revealed brief, low-frequency sounds, from $2 \mathrm{kHz}$ down, that occurred in groups of varying numbers (detail of a drumming bout from A. thomasi, Fig. 1). Three of the species in this study were found to perform these drumming events during calling songs (A. tinnulacita, A. tinnulenta, and A. thomasi) (Table 1). No drumming events were detected for $A$. exigua in the nine major echemes of calling songs analyzed for this species (these represent hours of recorded calling songs).

Table 1. Occurrence of drumming within calling songs of Anaxipha species (average $\pm \mathrm{SD}$ ).

\begin{tabular}{lccccc}
\hline \multicolumn{1}{c}{ Species } & Taps/bout & Taps/s & Syllables/s & Temp. $\left({ }^{\circ} \mathrm{C}\right)$ & $\mathbf{n}$ \\
\hline A. exigua & ND & ND & $39.35 \pm 0.834$ & 22.6 & $9^{*}$ \\
A. tinnulacita & $4.27 \pm 1.500$ & $18.00 \pm 1.525^{\mathrm{a}}$ & $11.20 \pm 0.233$ & 24.1 & 530 \\
A. tinnulenta & $2.83 \pm 0.578$ & $17.36 \pm 2.829^{\mathrm{ab}}$ & $4.82 \pm 0.045$ & 22.7 & 12 \\
A. thomasi & $7.28 \pm 0.813$ & $17.39 \pm 0.504^{\mathrm{b}}$ & $17.90 \pm 0.071$ & 22.1 & 34 \\
\hline
\end{tabular}

$\mathrm{ND}=$ not detected

${ }^{\mathrm{a}} p=0.161$.

$\mathrm{b} p=0.952$.

* song segments analyzed, otherwise $\mathrm{n}=$ number of drumming bouts measured 
Drumming bouts within calling songs were rare except for A. tinnulacita, which produced drumming bouts throughout long periods of calling songs. The rate of tapping (taps/s) in these calling song drumming bouts was somewhat similar across the three species at approximately 18 taps/s (range 14.53-19.53 taps/s, $n=576$ ), and the syllable rate of the calling songs varied across these species in a typical, species-specific pattern (Walker and Funk 2014) (Table 1). The range of the number of taps per drumming bout during calling songs was different across the three species, with A. tinnulacita giving 2-8 taps/bout, A. tinnulenta giving 2-4 taps/bout, and A. thomasi giving 6-9 taps/ bout (Table 2).

Table 2. Range of the number of taps per drumming bout by song type. ND = not detected

\begin{tabular}{lcc}
\hline \multirow{2}{*}{ Species } & \multicolumn{2}{c}{ Song Type } \\
\cline { 2 - 3 } & Calling & Courtship \\
\hline A. exigua & ND & $4-10(33)$ \\
A. tinnulacita & $2-8(1502)$ & $3-9(21)$ \\
A. tinnulenta & $2-4(12)$ & $4-9(98)$ \\
A. thomasi & $6-9(31)$ & $3-14(92)$ \\
\hline
\end{tabular}

Number in parentheses $=$ number of drumming bouts in the analysis .

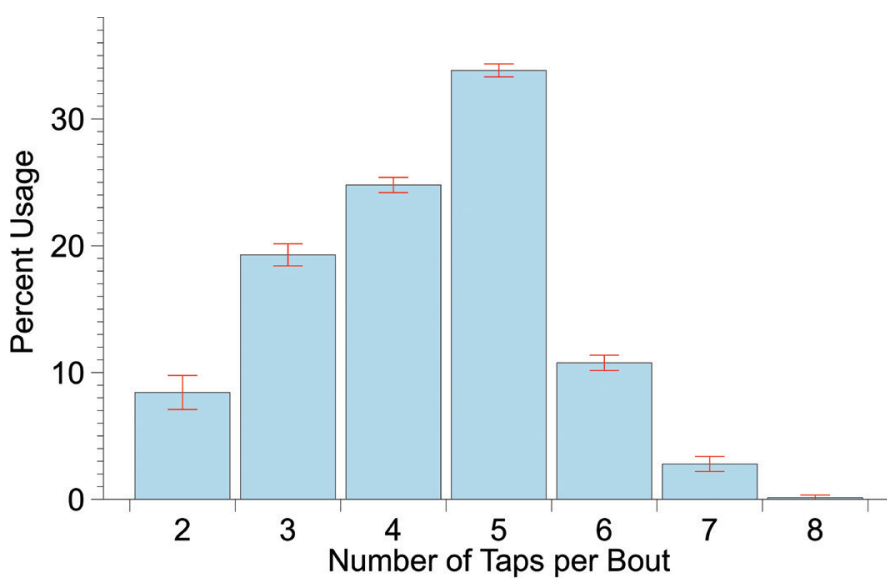

Fig. 2. Percent usage of different length drumming bouts during calling songs in A. tinnulacita. ( $\mathrm{n}=24$ songs; 1,503 tapping bouts; error bars are $\pm \mathrm{SD}$ of the means).
A. tinnulacita produced numerous drumming bouts during calling songs. Analysis of the different drumming bout types (number of taps per bout) used during calling songs showed that A. tinnulacita uses the three, four, and five taps per bout tap-type most of the time (Fig. 2). From one major echeme of calling song to the next, the use of drumming bouts was variable, but showed a pattern of more drumming bouts occurring during the first 40 percent and the last 20 percent of these calling songs (Fig. 3).

When males were placed in the same container with a conspecific female, all four species performed courtship songs. The males for the species in this study held their wings up, nearly perpendicular to their bodies, during calling and courtship singing. The courtship songs were different from calling songs in their overall amplitude and the amplitude envelope over time. Courtships songs were also broken into smaller echemes, particularly after the first several seconds of song during any particular courtship song bout (Fig. 4). Courtship songs also differed from calling songs in the shape and duration of the individual syllables that make up the echemes, with an increase in lower amplitude sounds between the louder syllables. These weaker sounds must be associated with

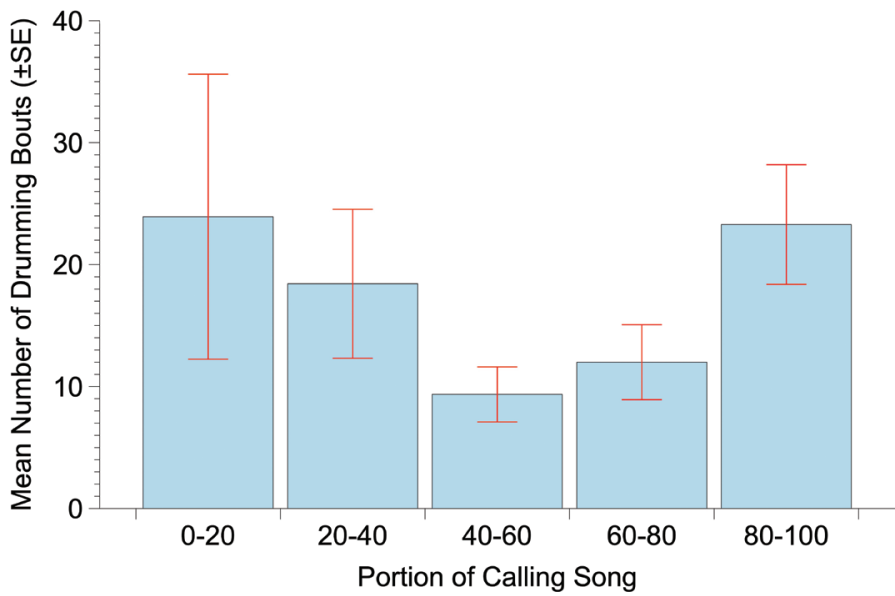

Fig. 3. Mean number of drumming bouts performed during different portions of calling songs in A. tinnulacita showing standard error of the means. The occurrence of drumming was variable from one calling song to the next. Consistently, more drumming bouts were given during the first 40 percent and the last 20 percent of the major echemes of calling song ( $\mathrm{n}=14$ songs, 1218 drumming bouts total).

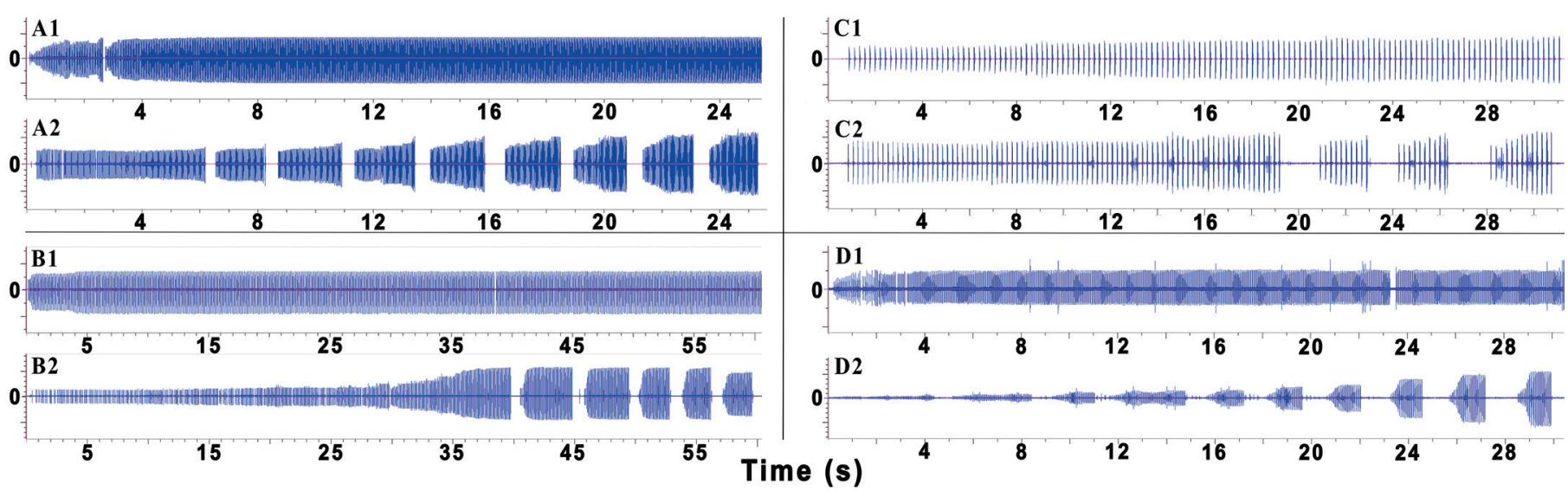

Fig. 4. Oscillograms of the calling and courtship songs of the four species of Anaxipha. A1. A. exigua calling song; A2. A. exigua courtship song; B1. A. tinnulacita calling song; B2. A. tinnulacita courtship song; C1. A. tinnulenta calling song; C2. A. tinnulenta courtship song; D1. A. thomasi calling song; D2. A. thomasi courtship song. All audio files were normalized to -3 dBFS for comparison. Y-axis represents amplitude and is analogous to dBFS (full scale). 


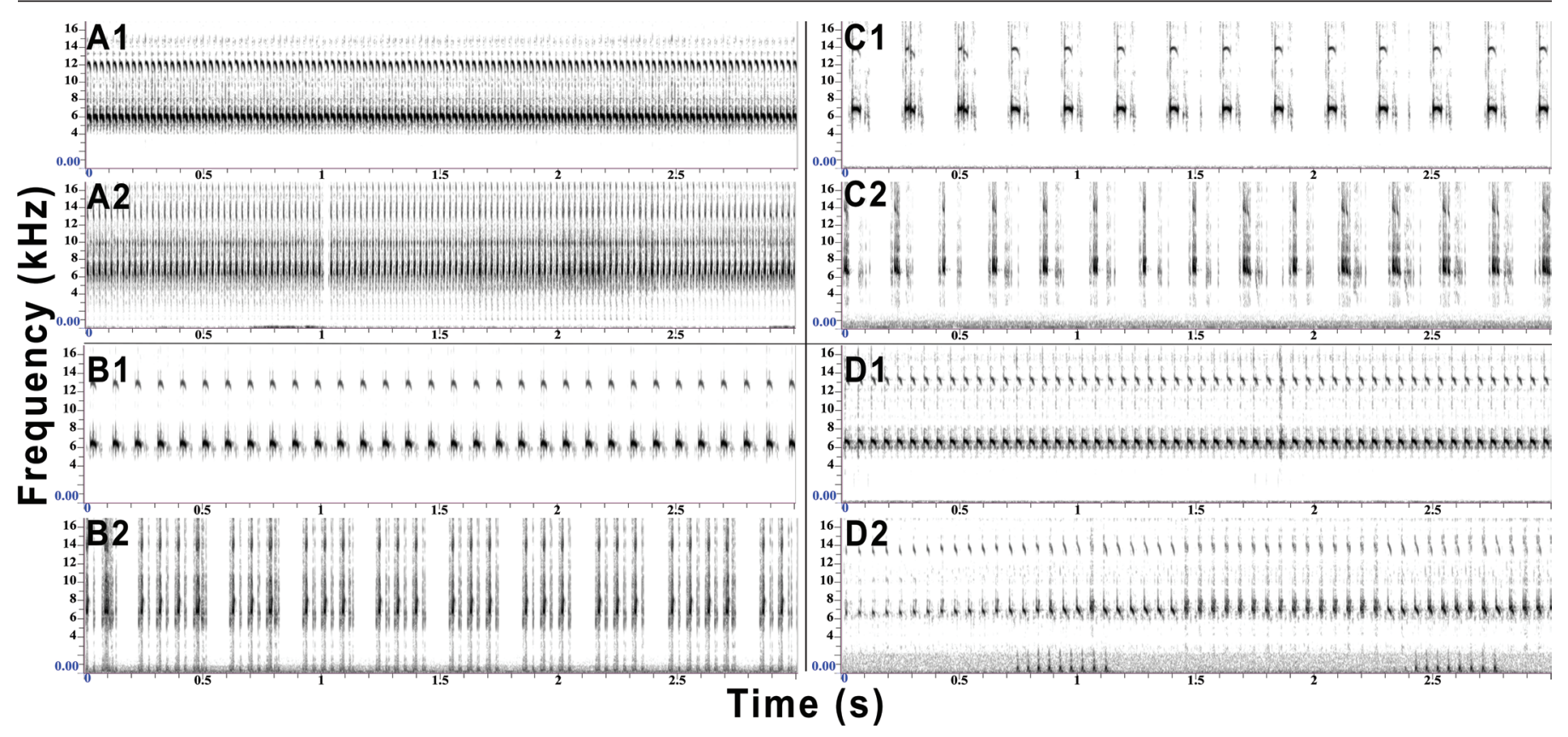

Fig. 5. Audio spectrograms of three seconds of calling and courtship songs of the four species of Anaxipha. A1. A. exigua calling song; A2. A. exigua courtship song; B1. A. tinnulacita calling song; B2. A. tinnulacita courtship song; C1. A. tinnulenta calling song; C2. A. tinnulenta courtship song; D1. A. thomasi calling song; D2. A. thomasi courtship song. Compared to calling song, the individual syllables of courtship songs are shorter, patterned differently, with more sounds associated with wing-opening movements (wing-dragging).

wing-opening movements (wing-dragging) (Fig. 5). The syllable duration within courtship songs was always significantly shorter when compared to the syllable duration of the calling songs for each species (Table 3). Due to the high skewness of the untransformed data, $p$-values were calculated from $t$-tests of Log10 transformed data comparing the sample means.

Table 3. Syllable duration comparison between song types (average $\pm \mathrm{SD}$ ). The syllable duration is statistically significantly shorter in courtship songs across the four species in this study. Numbers in parentheses are the number of syllables analyzed from each song type. Due to the significant skewness of the raw data, $p$-values were calculated from $t$-tests of Log 10 transformed data comparing the sample means.

\begin{tabular}{lccc}
\hline \multirow{2}{*}{ Species } & \multicolumn{2}{c}{ Syllable Duration (ms) } & \multirow{2}{*}{ p-value } \\
\cline { 2 - 3 } & Calling & Courtship & \\
\hline A. exigua & $17.61 \pm 2.662(961)$ & $2.83 \pm 0.468(102)$ & $<0.00001$ \\
A. tinnulacita & $28.06 \pm 0.875(480)$ & $12.63 \pm 4.764(480)$ & $<0.00001$ \\
A. tinnulenta & $36.11 \pm 1.967(583)$ & $5.34 \pm 1.805(103)$ & $<0.00001$ \\
A. thomasi & $16.85 \pm 1.625(540)$ & $13.61 \pm 5.655(362)$ & $<0.00001$ \\
\hline
\end{tabular}

All four species in this study also produced numerous drumming bouts during courtship songs. The range of the number of taps per drumming bout was higher in courtship songs than in calling songs, with A. exigua giving 4-10 taps/bout, A. tinnulacita giving 3-9 taps/bout, A. tinnulenta giving 4-9 taps/bout, and A. thomasi giving 3-14 taps/bout (Table 2). The average number of taps/second in courtship song drumming bouts showed that the rates were statistically different between all species ( $p$-value $\leq$ $0.0022)$; the syllable rate of the courtship songs varied across species, similar to their individual calling song rates (Table 4). While drumming bouts were given throughout courtship singing for $A$. exigua and $A$. thomasi, it was found that drumming bouts were
Table 4. Average taps/bout and taps/s within courtship songs of the four Anaxipha species compared to the average syllable rate of their respective courtship song during these tapping bouts $( \pm S D)$.

\begin{tabular}{lccccc}
\hline \multicolumn{1}{c}{ Species } & Taps/bout & Taps/s & Pulses/s & Temp. $\left({ }^{\circ} \mathrm{C}\right)$ & $\mathbf{n}$ \\
\hline A. exigua & $6.61 \pm 1.340^{\mathrm{a}}$ & $19.91 \pm 0.941$ & $39.15 \pm 0.952$ & 22.6 & 33 \\
A. tinnulacita & $6.19 \pm 1.540^{\mathrm{a}}$ & $20.67 \pm 0.667$ & $13.21 \pm 0.067$ & 23 & 21 \\
A. tinnulenta & $6.93 \pm 0.865^{\mathrm{a}}$ & $17.58 \pm 1.130$ & $4.63 \pm 0.053$ & 22.1 & 98 \\
A. thomasi & $8.41 \pm 3.210$ & $23.15 \pm 0.715$ & $20.04 \pm 0.221$ & 23.5 & 92 \\
\hline
\end{tabular}

$\mathrm{n}=$ the number of drumming bouts analyzed.

a $p$-values from $t$-test comparisons of means shows these means to be statistically similar. All other comparisons were statistically different at the 95\% level.

typically given later in courtship songs for A. tinnulacita and A. tinnulenta (Fig. 6). The peak audio frequency of the taps of drumming bouts during calling and courtship songs were similar within each species and were no doubt related to the substrate that the males were tapping on (plastic containers). However, the taps created by A. exigua were consistently of a significantly lower peak carrier frequency than those produced by the other species in this study ( $p<0.0001)$, with the carrier frequencies of $A$. tinnulacita and $A$. tinnulenta $(p=0.21)$ and $A$. tinnulacita and $A$. thomasi ( $p=$ 0.367 ) being statistically similar (Table 5 ).

During courtship songs, tapping within any particular drumming bout increases in peak amplitude in all four species, with the ending of a drumming bout being statistically louder than the beginning, with a $p$-value of $<0.0001$ for each comparison (Fig. 7).

A. thomasi was the only species in this study that performed jumping motions during the silent periods between echemes within courtship songs. The male would repeatedly jump backwards slightly, with irregular, rapid motions creating sounds when coming to rest on the substrate. These motions created low-frequency sounds similar in carrier frequency to those in typical tapping bouts, but the pattern of these sounds was very different from the tapping bouts given during courtship or calling song echemes 

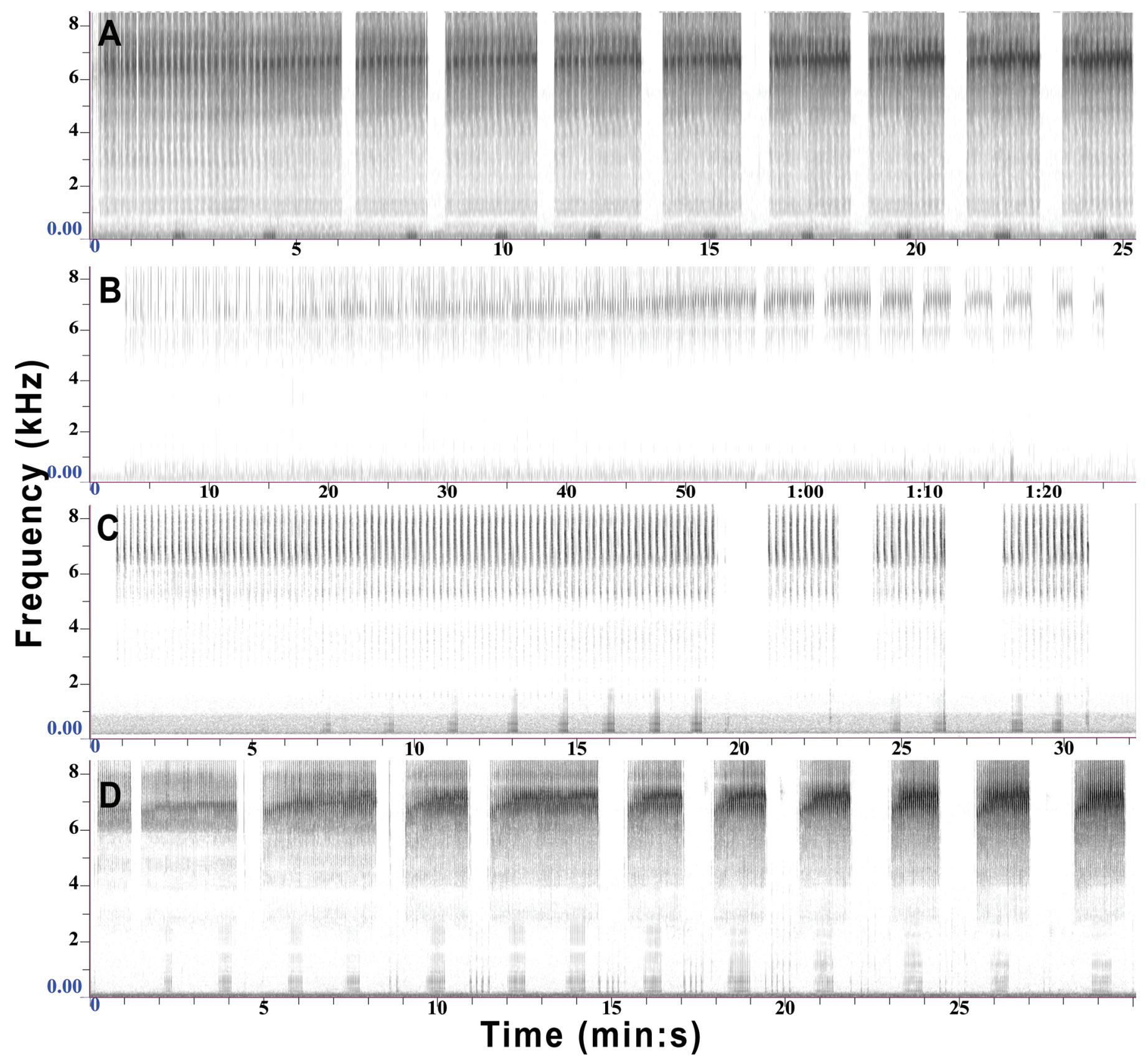

Fig. 6. Audio spectrograms of courtship songs of four species of Anaxipha showing drumming bouts (below $2 \mathrm{kHz}$ ) and tegminal sounds (above $4 \mathrm{kHz}$ ). Low frequencies (below $2 \mathrm{kHz}$ ) were enhanced to better show the low-frequency drumming bouts. A. Anaxipha exigua, dark areas below $1 \mathrm{kHz}$ are drumming bouts; B. Anaxipha tinnulacita, fine, dark lines after 1:05 (min:sec) are the drumming bouts; C. Anaxipha tinnulenta, the dark areas after $5 \mathrm{sec}$ and below $2 \mathrm{kHz}$ are the drumming bouts; D. Anaxipha thomasi, the compact dark areas below $2 \mathrm{kHz}$ are the drumming bouts. The clustered, individual taps between drumming bouts are sounds made by the insect jumping repeatedly and rapidly between echemes during the courtship display. Note that the time scales for each courtship song are different, as each species courtship song length is different and variable.

(Fig. 6D at 9, 11.5, 15, 19.5, 20, 22.5, and $25 \mathrm{sec}$ ) (a video file of this behavior is at ML488781). These movements and sounds were not studied further here.

Also noted during close examination of these species' courtship interactions were palp-drumming sessions performed by the males typically during non-singing portions of the courtship interactions when the male and female were in close proximity (video files of this behavior are at ML488780, ML488782, and ML488784). These palp-drumming sounds were of extremely low amplitude and required significant amplification of the audio to hear them; they were not studied further here.

\section{Discussion}

This is the first report showing that members of the genus Anaxipha use substrate-borne vibrations as a possible method of communication and the first to demonstrate that these trigs produce courtship songs that are distinctly different from their 


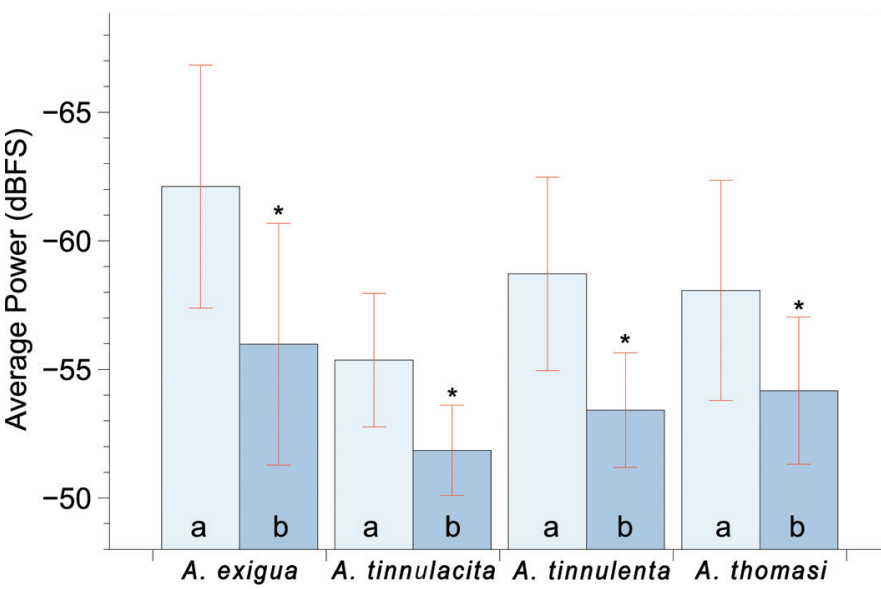

Fig. 7. Examination of the means of the average power of the combined first two and the combined last two taps of drumming bouts in courtship songs \pm SD. In nearly all instances, tapping becomes louder during an individual drumming bout within courtship songs across all four species. Numbers closer to the abscissas are louder. $\mathrm{a}=$ average of the first two taps, $\mathrm{b}=$ average of the last two taps in bouts of four taps or more. ${ }^{*}=t$-tests comparing the means of first two taps to the last two taps, within each species, showed the $p$-values were all $<0.0001$, showing that the taps are significantly louder at the end of drumming bouts (A. exigua $\mathrm{n}=5$ songs, 45 drumming bouts; A. tinnulacita $\mathrm{n}=4$, 29; A. tinnulenta $\mathrm{n}$ =4,98; A. thomasi $\mathrm{n}=5,75)$.

Table 5. Average of the peak frequencies in $\mathrm{Hz}$ of highest amplitude frequency of taps of drumming bouts for the specific container type in which these insects were kept.

\begin{tabular}{lcc}
\hline \multicolumn{1}{c}{ Species } & Peak Frequency \pm SD & n \\
\hline A. exigua & $89.8 \pm 35.59$ & 5,48 \\
A. tinnulacita & $277.0 \pm 58.12^{\mathrm{ab}}$ & 5,33 \\
A. tinnulenta & $266.5 \pm 27.84^{\mathrm{a}}$ & 5,73 \\
A. thomasi & $287.8 \pm 55.96^{\mathrm{b}}$ & 5,72 \\
\hline
\end{tabular}

a $p$-values show no statistically significant difference between these two species $(\mathrm{p}=$ $0.21)$.

${ }^{\mathrm{b}} p$-values show no statistically significant difference between these two species ( $\mathrm{p}=$ 0.367 )

$p$-values for comparisons of A. exigua to the other three species were all $p<0.0001$.

$\mathrm{n}=$ number of songs, total number of drumming bouts.

typical calling songs. The use of courtship songs in other Gryllidae is well known (Alexander and Otte 1967), but little is known about the acoustic courtship behavior of the Trigonidiinae, with mating behavior reported in only a few species (Spooner 1972, Ingrisch 1977, Mendelson and Shaw 2002, Fergus et al. 2011, Shaw and Khine 2004, Funk 2016, Centeno and Zefa 2019). Males of all four species in this study produced songs that were statistically different from their calling songs when in the presence of conspecific females, and all four species exhibited drumming during courtship singing. While calling songs consisted of long, rarely broken echemes that crescendo quickly to full volume, courtship song echemes crescendo more slowly and are broken into more discrete intervals, typically in the later portion of the courtship song.

The high amplitude of calling songs would seem to make it harder for females to locate a displaying male in the tangle of vegetation typical of the habitat types used by these insects. The use of substrate-borne vibrations (drumming) certainly would make it easier for searching females to find courting males (Hill 2001, 2009, Eriksson et al. 2011, Caldwell 2014, Yack 2016). Further investigations into this mode of communication within the Anaxipha will be required to determine the range and efficacy of these vibrations to facilitate the orientation of searching females. The use of laser-vibrometers or sensitive transducers may be ideal for this work.

Three of the species studied here used drumming during calling songs. While these substrate-borne vibrations would certainly aid searching females looking for a perspective mate, it is unclear why A. exigua did not appear to perform drumming during calling song bouts, while drumming bouts were readily detected in the other three species studied here. Also, it is interesting that drumming bouts were easily detected in the courtship songs of A. exigua. Further study of A. exigua's calling songs in a different container type would be illuminating to ensure that some aspect of the structure of the singing cages used here was not preventing the insect from producing these particular sounds.

It appears that the combination of calling song syllable rate, courtship song syllable rate, and the tapping rate in drumming bouts would clearly define each of these four species as distinct and separate to listening females. The change in the syllable length and syllable loudness in courtship songs along with the enhanced use of wing-closing sounds, the change in the pattern and amplitude envelope, and the increase in production of longer drumming bouts (more taps/bout) would clearly signal to the female the presence of a receptive male of the correct species.

Additional maneuvers and vibrations were only observed in A. thomasi, with males jumping (irregular, rapid, backward motions) during the silent portions of courtship encounters. It appeared that the sounds were created by his feet hitting the substrate as he lands from the jumping motions. These jumping sessions were only performed when he was not creating sounds with his tegmina. Also, males did not appear to drum during these jumping displays. The significance of these additional displays requires further investigation.

In all the species in this study that were videoed during courtship displays, males were observed to perform palp-drumming during quiet portions of the courtship display. These sounds were extremely faint. Future study of palp-drumming will require very sensitive equipment, such as laser-vibrometry, to fully detect what the males and the females are communicating to one another during these easily overlooked courtship interactions.

\section{Acknowledgements}

I am grateful to the Potomac Valley Audubon Society for granting me permission to study these species at their preserve and for the permits to collect specimens. I am grateful to Dr. Thomas J. Walker, Professor Emeritus, University of Florida, for his generous sharing of his knowledge and data. I would like to thank Dr. David Funk for sharing information and comments about these species and their songs. I am thankful to the Orthoperists' Society for providing funding to publish this paper. Thanks also to the anonymous referees. I am also grateful for the assistance of Dr. Tracy Leskey and the JOR editor for invaluable improvements to this manuscript. All audio recordings associated with this project are archived at the Macaulay Library, Cornell Laboratory of Ornithology, ML numbers 305982-306011 and $488780-488784$. 


\section{References}

Alexander RD, Otte D (1967) The evolution of genitalia and mating behavior in crickets (Gryllidae) and other Orthoptera. Miscellaneous Publications of the Museum of Zoology Michigan 133: $1-70$.

Baker E, Chesmore D (2020) Standardisation of bioacoustic terminology for insects. Biodiversity DataJournal 8: e54222. https://doi. org/10.3897/BDJ.8.e54222

Caldwell MS (2014) Interactions between airborne sound and substrate vibration in animal communication. In: Studying vibrational communication. Springer Berlin Heidelberg, 65-92. https://doi. org/10.1007/978-3-662-43607-3_6

Centeno E, Zefa E (2019) The complex communication signals in the mating behavior of the tropical cricket Cranistus colliurides Stål, 1861 (Orthoptera: Grylloidea; Trigonidiidae: Phylloscyrtini). Zootaxa 4623: 571-576. https://doi.org/10.11646/zootaxa.4623.3.9

Cocroft RB, Tieu TD, Hoy RR, Miles RN (2000) Directionality in the mechanical response to substrate vibration in a treehopper (Hemiptera: Membracidae: Umbonia crassicornis). Journal of Comparative Physiology - A Sensory, Neural, and Behavioral Physiology 186: 695-705. https://doi.org/10.1007/s003590000123

Cokl A, Virant-Doberlet M (2003) Communication with substrateborne signals in small plant-dwelling insects. Annual Review of Entomology 48: 29-50. https://doi.org/10.1146/annurev. ento.48.091801.112605

Eriksson, A, Anfora G, Lucchi A, Virant-Doberlet AM, Mazzoni V (2011) Inter-plant vibrational communication in a leafhopper insect. PLoS ONE 6: e19692. https://doi.org/10.1371/journal.pone.0019692

Fergus DJ, Decarvalho TN, Shaw KL (2011) Genetically regulated temporal variation of novel courtship elements in the Hawaiian cricket genus Laupala. Behavior Genetics 41: 607-614. https://doi.org/10.1007/ s10519-010-9397-2

Funk DH (2016) Mating behavior of Phyllopalpus pulchellus Uhler (Orthoptera: Gryllidae: Trigonidiinae). Journal of Orthoptera Research 25: 7-13. https://doi.org/10.1665/034.025.0103
Hershberger WL (2021) Calling and courtship songs of the rare, robust ground cricket, Allonemobius walkeri. Journal of Orthoptera Research 30: 81-85. https://doi.org/10.3897/jor.30.63692

Hill PSM (2001) Vibration and animal communication: A review. American Zoologist 41: 1135-1142. https://doi.org/10.1093/icb/41.5.1135

Hill PSM (2009) How do animals use substrate-borne vibrations as an information source? Naturwissenschaften 96: 1355-1371. https://doi. org/10.1007/s00114-009-0588-8

Ingrisch S (1977) Das Stridulationsorgan der Käfergrille Trigonidium cicindeloides (Orthoptera: Gryllidae: Trigoniinae) und Beobachtungen zur Eidonomie und Ethologie. Entomologica Germanica 3: 324-332. https://doi.org/10.1127/entom.germ/3/1977/324

Mendelson TC, Shaw KL (2002) Genetic and behavioral components of the cryptic species boundary between Laupala cerasina and L. kohalensis (Orthoptera: Gryllidae). Genetica 116: 301-310. https://doi. org/10.1023/A:1021244812270

Michelsen A, Fink F, Gogala M, Traue D (1982) Plants as transmission channels for insect vibrational songs. Behavioral Ecology and Sociobiology 11: 269-281. https://doi.org/10.1007/BF00299304

Saussure H de (1874) Mission scientifque au Méxique et dans L'Amérique centrale 6: 30 .

Say T (1825) Descriptions of new Hemipterous Insects collected in the expedition to the Rocky Mountains, performed by order of Mr. Calhoun, Secretary of War, under command of Major Long. Journal of the Academy of Natural Sciences of Philidelphia 4: 307-345.

Shaw KL, Khine AH (2004) Courtship behavior in the Hawaiian cricket Laupala cerasina: males provide spermless spermatophores as nuptial gifts. Ethology 110: 81-95. https://doi.org/10.1046/j.1439-0310.2003.00946.x Spooner JD (1972) Courtship in Falcicula hebardi (Orthoptera: Gryllidae, Trigonidiinae). Annals of the Entomological Society of America 65: 1419-1419. https://doi.org/10.1093/aesa/65.6.1419

Walker TJ, Funk DH (2014) Systematics and Acoustics of North American Anaxipha (Gryllidae: Trigonidiinae). Journal of Orthoptera Research 23: 1-38. https://doi.org/10.1665/034.023.0102

Yack J (2016) Vibrational signaling. In: Pollack GS, Mason AC, Popper A, Fay RR (Eds) Insect Hearing. Springer, Cham, 99-123. https://doi. org/10.1007/978-3-319-28890-1_5 